\title{
Fresh Osteochondral Allografting in the Treatment of Osteochondritis Dissecans of the Talus
}

\author{
by Ali Abadi DPM,MS ${ }^{1 \otimes}$, Raymond Ferrara DPM ${ }^{2 \otimes}$
}

The Foot and Ankle Online Journal 3 (7): 3

A 42 year-old female with persistent ankle pain secondary to trauma of the right ankle is presented. Magnetic resonance imaging revealed an osteochondral lesion of the medial equatorial aspect of the talar bone. After exhausting several type of conservative treatments, such as pain management, ice therapy, NSAID, injection and immobilization, surgical intervention was necessary to treat the osteochondritis dissecans.

Key words: Osteochondritis Dissecans, Osteochondral Allograft, Articular cartilage transplantation, talus.

Published: July, 2010

This is an Open Access article distributed under the terms of the Creative Commons Attribution License. It permits unrestricted use, distribution, and reproduction in any medium, provided the original work is properly cited. (The Foot and Ankle Online Journal (www.faoj.org)

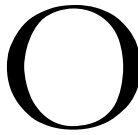
steochondritis Dissecans (OCD) was initially described by Alexander Monro (primus) in 1738. ${ }^{1}$ In 1870, James Paget described the disease process for the first time, but it was not until 1887 that Franz König published a paper on the cause of loose bodies in the joint. ${ }^{2}$ König named the disease "osteochondritis dissecans", ${ }^{3}$ describing it as a subchondral inflammatory process of the knee, resulting in a loose fragment of cartilage from the femoral condyle. In 1922, Kappis described this process in the ankle joint. ${ }^{4} \quad$ On review of all literature describing transchondral fractures of the talus, Berndt and Harty developed a classification system for staging of osteochondral lesions of the talus (OLTs). ${ }^{5}$

Address correspondence to: Dr. Ali Abadi, Virtua hospital,West jersey, 101 Carnie Blvd. Voorhees NJ 08043 Email:aa78@Georgetown.edu .

\footnotetext{
${ }^{1}$ Dr. Ali Abadi, Virtua hospital, West jersey, 101 Carnie Blvd. Voorhees NJ 08043.

${ }^{2}$ Dr Raymonfd Ferrera attending at Virtua Hosital, West jersey, 101 Carnie Blvd. Voorhees NJ 08043
}

In 2001, Scranton and McDermott added a fifth stage to the Berndt and Harty classification system in order to describe the cases of patient in whom the cartilage cap is intact with the lesion involving a subchondral cyst within the talar dome. ${ }^{6}$ The term osteochondritis dissecans has persisted, and has since been broadened to describe a similar process occurring in many other joints, including the knee, hip, elbow, and metatarsophalangeal joints.

\section{Case Report}

A 42 year-old female presented with history of sever right ankle pain. The patient stated that she has deep ankle pain and repeatedly "twists her ankle". On physical examination the region of pain was localized along the anteromedial aspect of the right talus. The area was tender to direct pressure. There was evidence of swelling at the right medial malleolar, but no signs of acute trauma, or bruising were noted. The ankle range of motion is preserved. Weight bearing radiographs of the ankle revealed osteochondral lesions. 


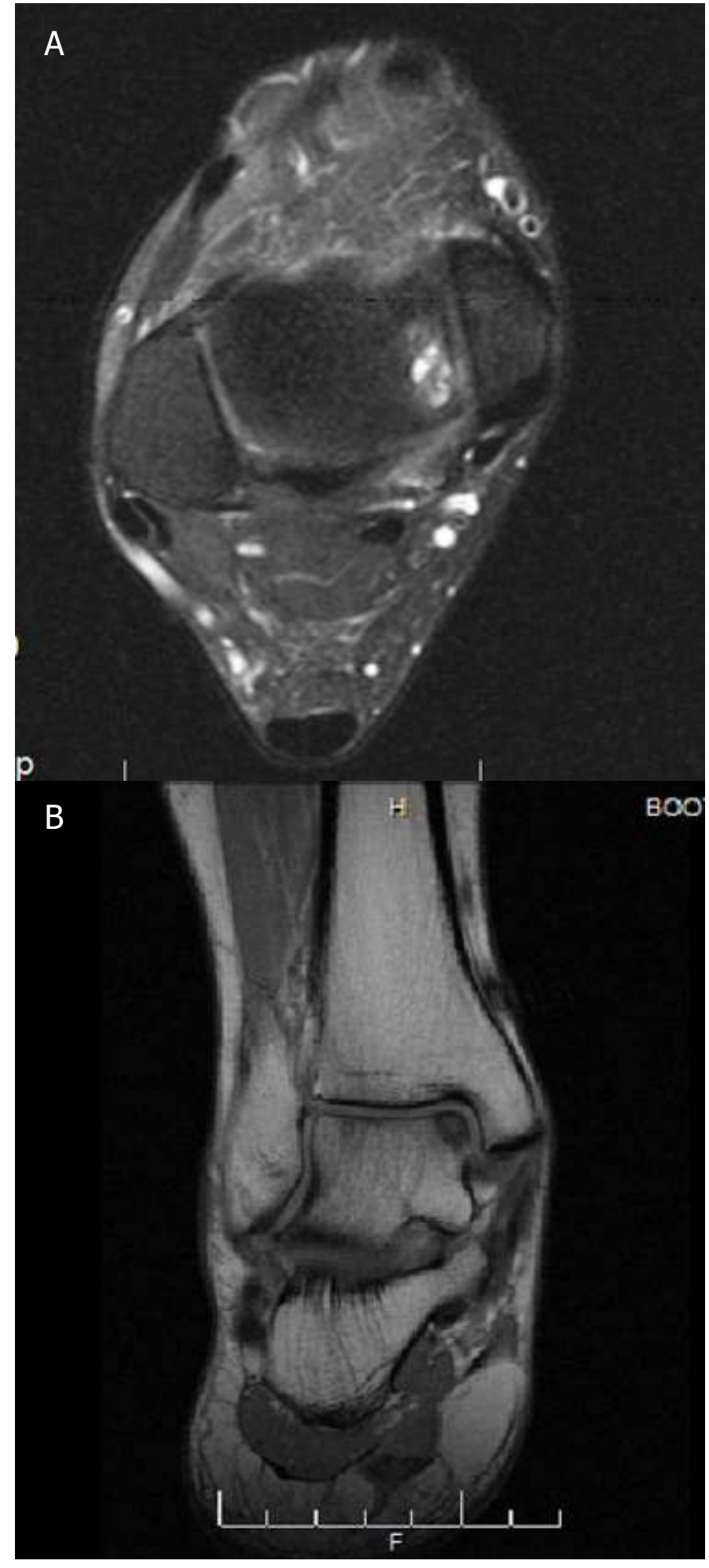

Figure 1A and 1B Magnetic resonance imaging demonstrating the osteochondral defect. A) The axial view, B) coronal view.
Magnetic resonance imaging (MRI) of the right ankle revealed an osteochondral defect involving the medial talar dome, without associated subchondral collapse. There is a T2 hyperintense and T1 hypointense osteochondral defect, measures $5 \mathrm{~mm}$ in transverse extent x $6 \mathrm{~mm}$ in cranicaudal extent. (Fig.1A and B)

The ankle mortis is symmetric. There is a surrounding bone marrow edema along the superomedial talar dome. It also revealed mild fluid within the retrocalcaneal bursae and minor tenosynovitis of the medial and lateral ankle tendons. Laboratory examination included corpuscular blood count with differential count, white blood cell count, rheumatoid factor, C-reactive protein, erythrocyte sedimentation rate, and serum uric acid are all unremarkable. Osteochondral allograft was obtain from thirteen year old fresh cadaver and supplied by Arthrex Inc.

\section{Surgical Technique}

The surgical procedure was performed under Monitored anesthesia care (MAC) combined with local infiltrative nerve block. The patient was positioned supine on the operating table. Preoperative antibiotic ( 2 grams Cefazolin ) were given at the beginning of the case. A pneumatic ankle tourniquet is placed on the mid-calf and inflated to $250 \mathrm{mmHg}$. The skin was prepped and draped from toes to mid calf.

A $6 \mathrm{~cm}$ longitudinal incision was made directly over the medial malleolus. (Fig. 2) The incision was then carried down through the subcutaneous tissue using sharp and blunt dissection. Care was taken to avoid all vital neurovascular structures. The talar dome and tibial plafond was located and marked on the skin utilizing the intraoperative fluoroscopy. (Fig. 3) The medial malleolus is predrilled with two 0.045 pins at a slightly divergent angles to help prevent proximal slippage of the medial malleolus during screw insertion. These pins are overdrilled with Arthrex 3.4 $\mathrm{mm}$ cannulated Trim-It Drill Bit across the medial malleolus and into the tibial plafond. The holes are then tapped. (Fig. 4) A V-shaped osteotomy was performed and medial malleolus carefully pulled inferiorly to expose the talus. (Fig. 5) 


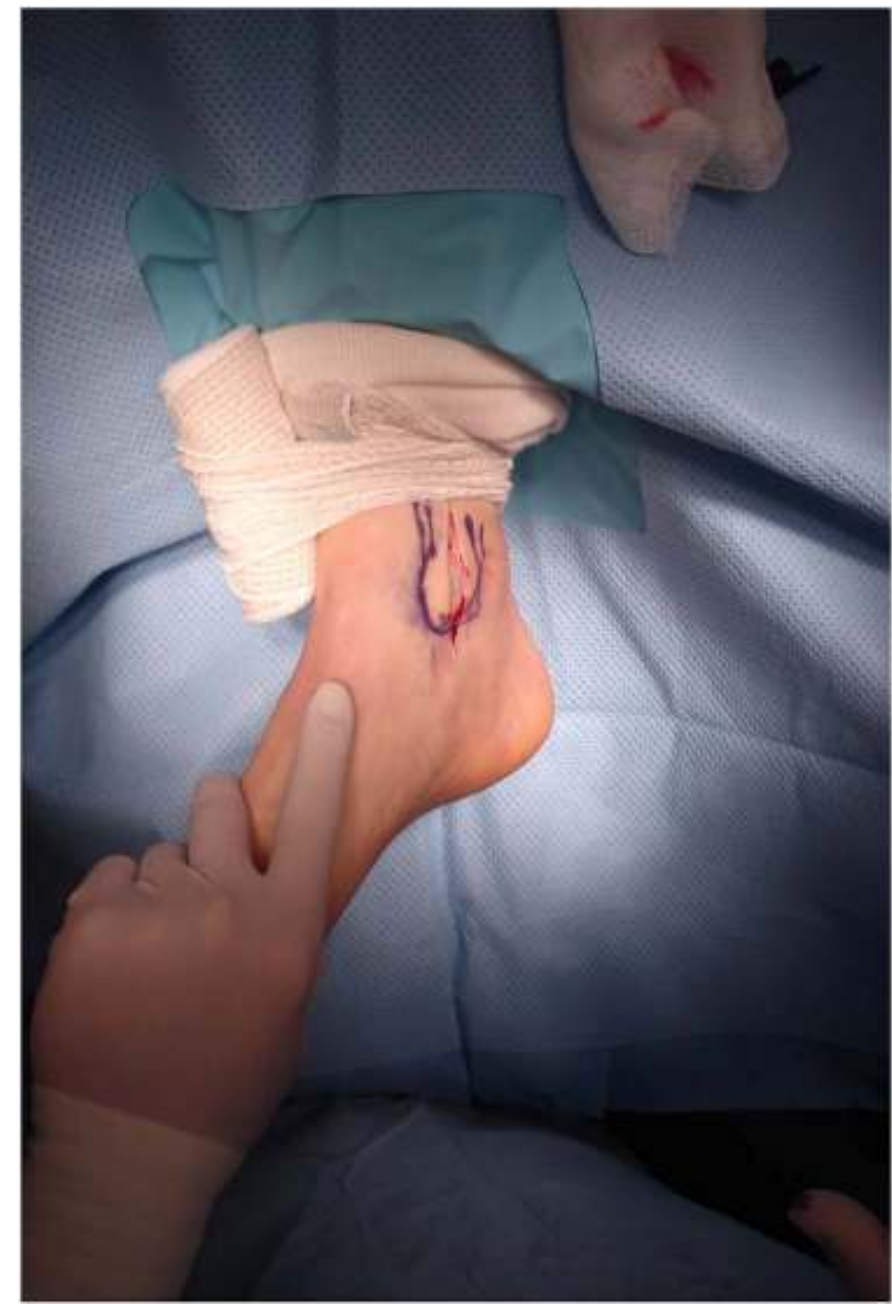

Figure 2 A $6 \mathrm{~cm}$ longitudinal incision is made along the medial malleolus.

The posterior tibialis and the flexor hallucis longus tendons are protected with small retractors. The talar lesion is drilled perpendicularly and centrally with the $2.4 \mathrm{~mm}$ guide pin. The guide pin is advanced to a depth of $15-20 \mathrm{~mm}$. The guide pin is then overdrilled with the appropriate size cannulated Headed Reamer to a depth of at least $12 \mathrm{~mm}$. (Fig. 6) The cannulated OATS Alignment Rod is introduced over the guide pin, which measures the diameter and depth of the pilot hole. At this point we covered the surgical site with saline soaked gauze and directed our attention to the Allograft bone. (Fig. 7) After matching the defected cartilage site to the donor site the Arthrex OATS $6 \mathrm{~mm}$ donor harvester was used.

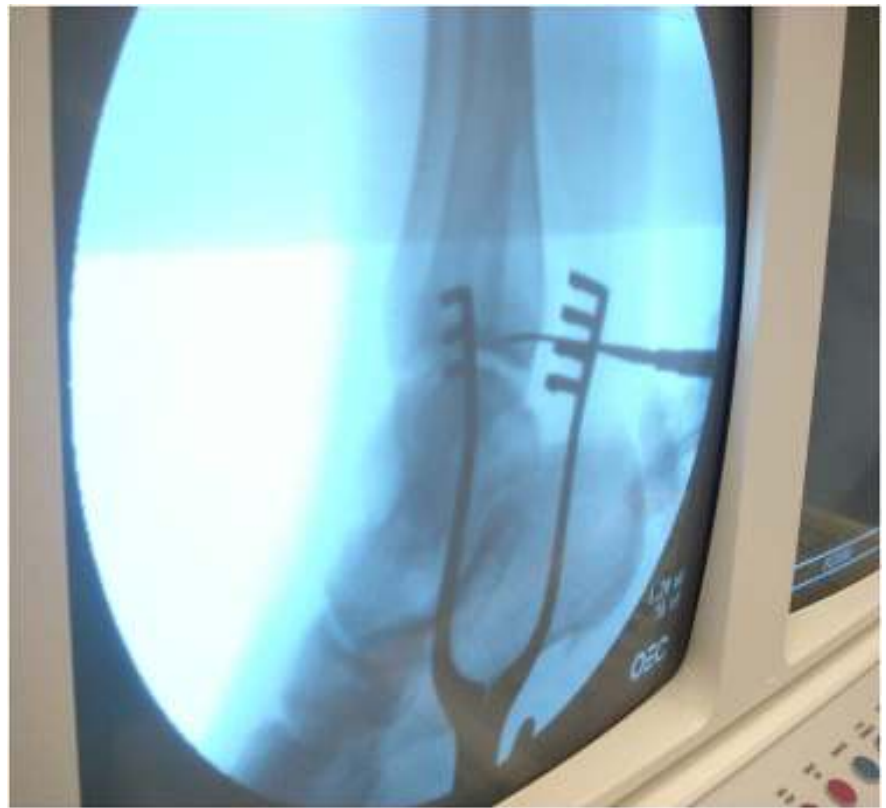

Figure 3 intraoperative fluoroscopic view showing the tibial plafond.

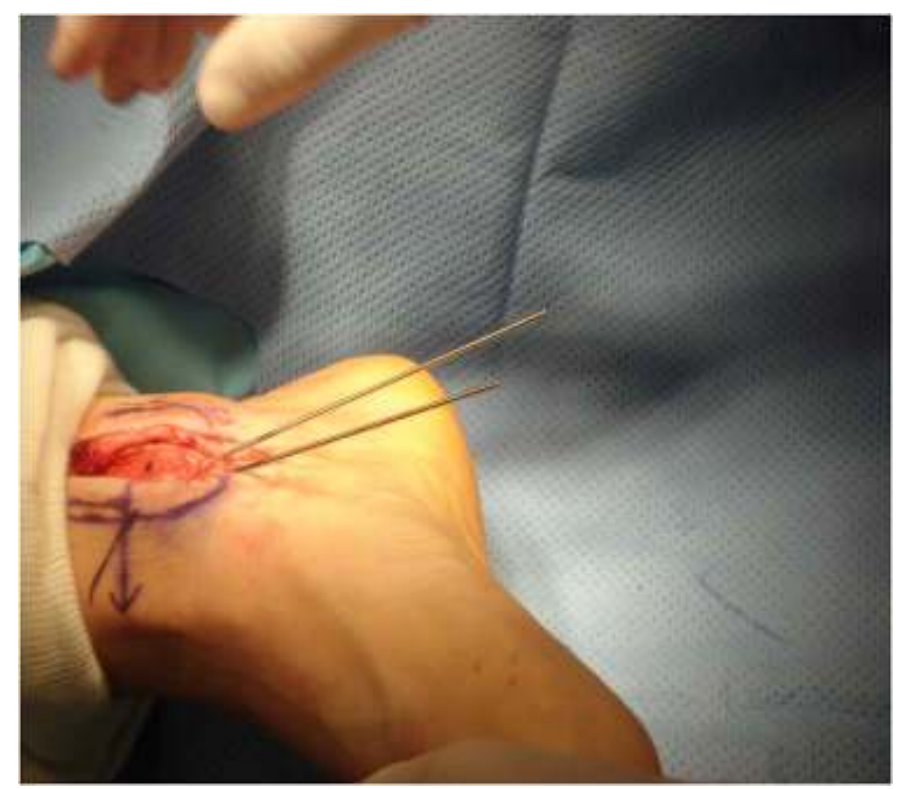

Figure 4 The medial malleolus is marked at the tibial plafond and the Arthrex $3.4 \mathrm{~mm}$ cannulated Trim-It wire is then placed in the tibia. 


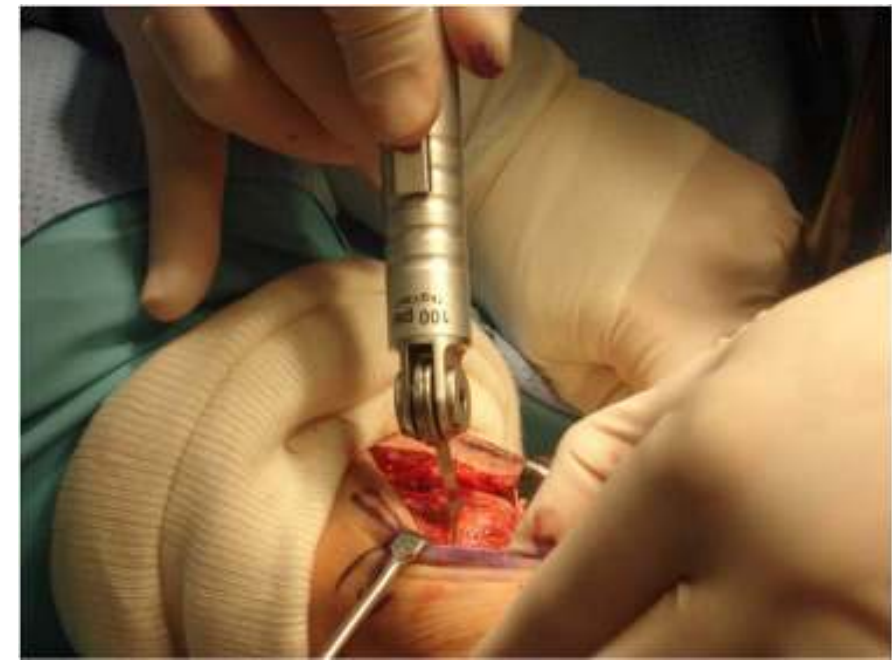

Figure 5 An intraoperative photograph demonstrating the $\mathrm{V}$-shaped osteotomy on medial malleolus to gain exposure to the OCD lesion.

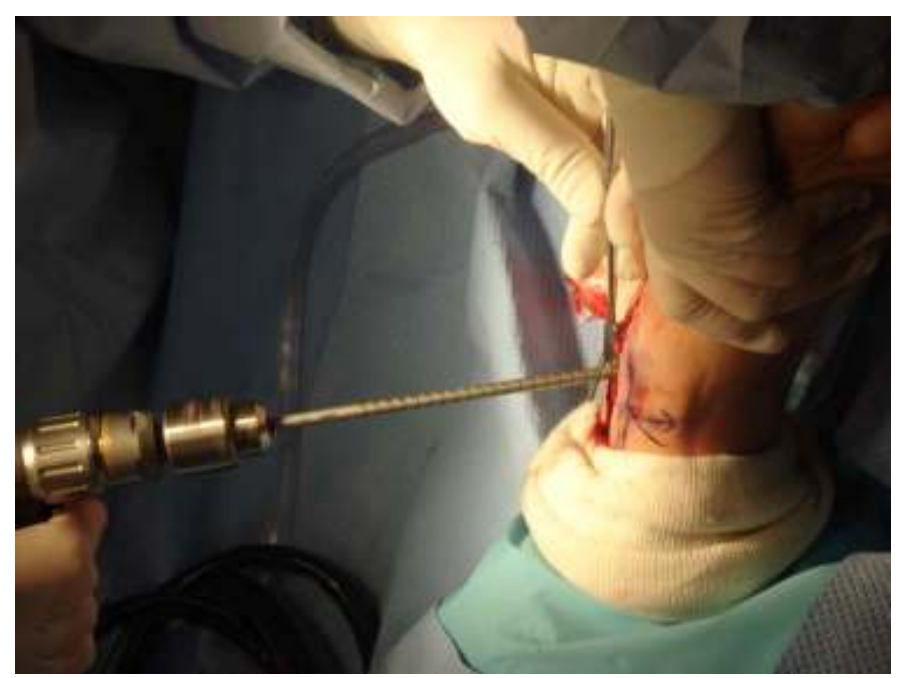

Figure 6 After placement of guide wire, the defect is then reamed.

We drove the harvester into to the donor talus, at 90 degrees, and twisted it clockwise 90 degrees under pressure and then full counter clockwise revolution. (Fig. 8) The tube and the raft were then withdrawn. Then we inserted the graft into the recipient hole in the talus. We utilized the large end of the tamp for tapping the graft into the graft site and made sure there is no protrusion. (Fig. $9 \mathrm{~A}-\mathrm{C}$ )

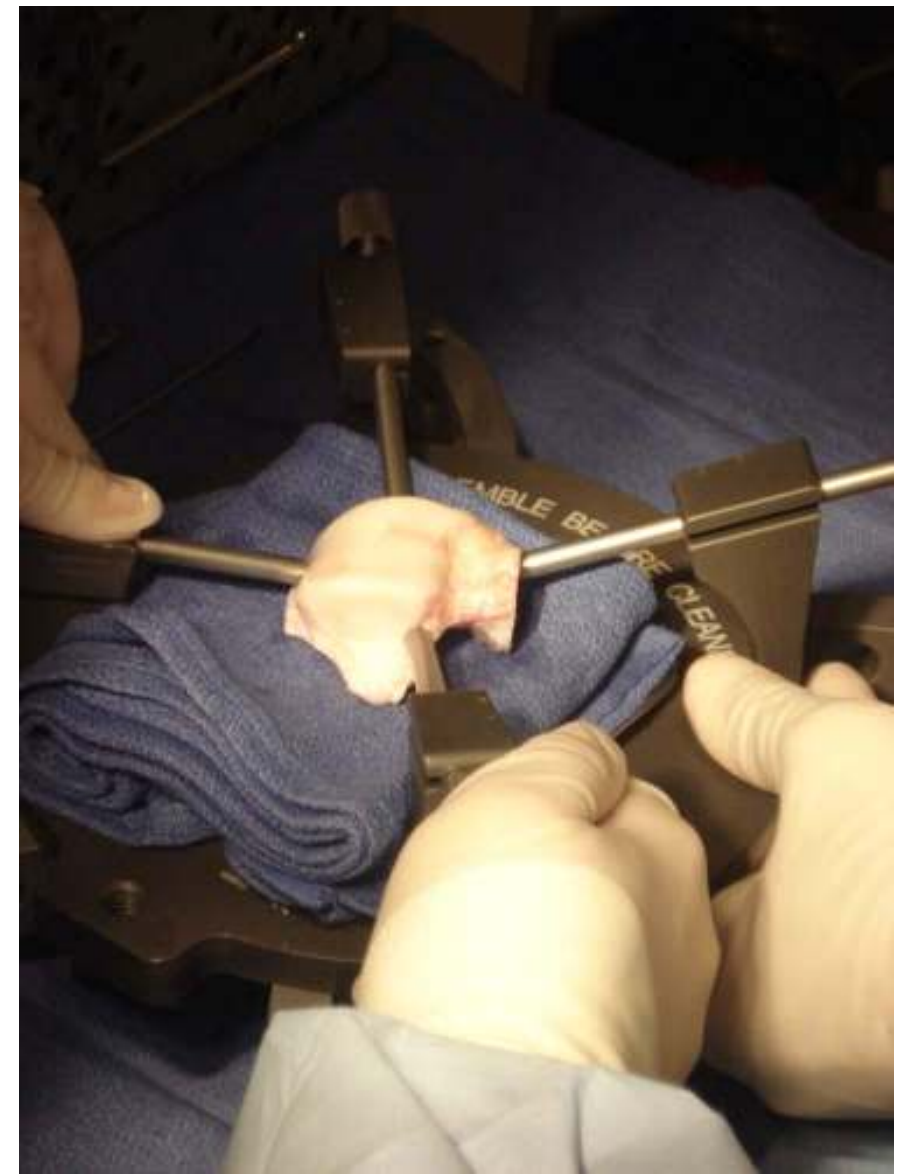

Figure 7 Fresh donor cadaver bone of the talus.

The medial malleolus is replaced back to its anatomical position. The Arthrex 0.045 pins reinserted back into the cannulated holes. Two $4.5 \mathrm{~mm}$ cannulated screws were driven up the holes while the medial malleolus is held in a position of anatomic reduction. (Fig. $10 \mathrm{~A}$ and $10 \mathrm{~B}$ )

\section{Discussion}

Articular cartilage disease can eventually lead to debilitating injury because of the body's inability to repair this important tissue. OCD is a pathologic process in which a fragment of subchondral bone becomes avascular and can separate from the surrounding tissue. 


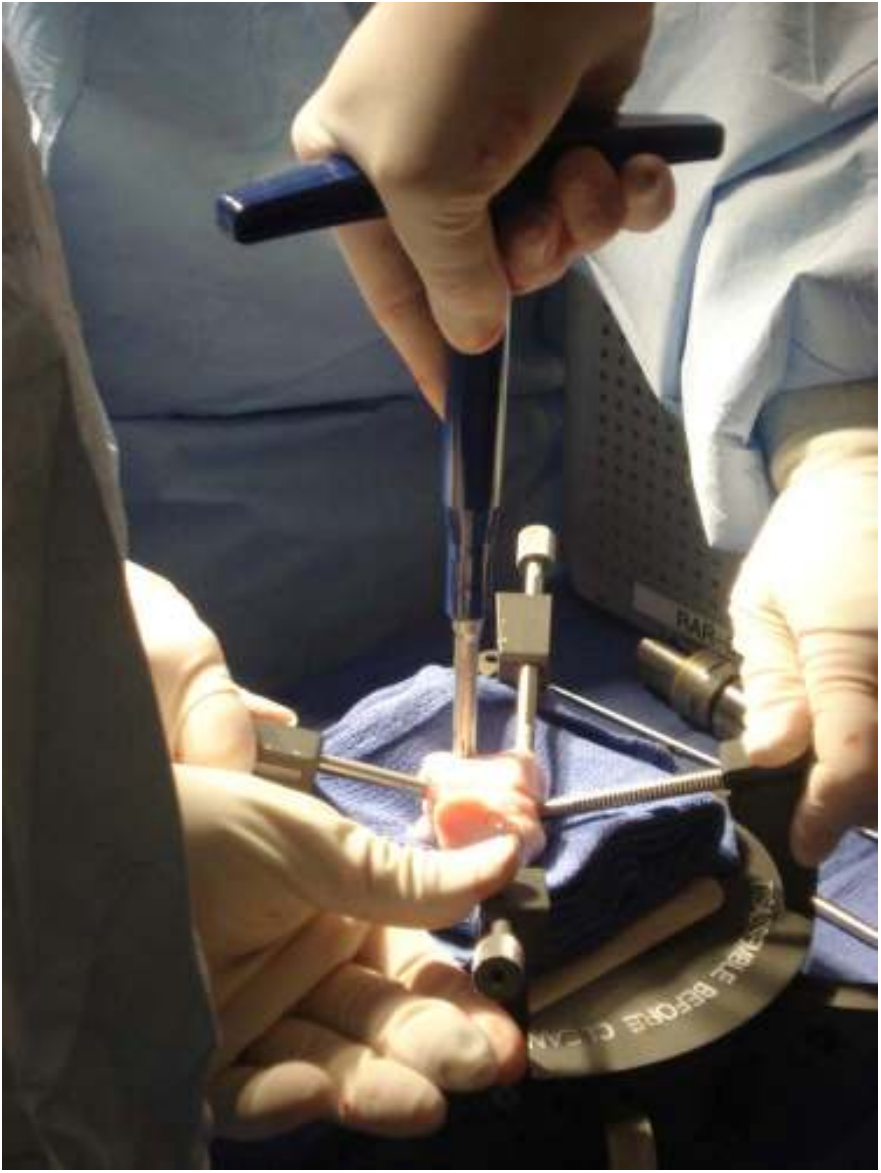

Figure 8 The Arthrex OATS $6 \mathrm{~mm}$ donor harvester is being twisted clockwise and counterclockwise to secure the donor graft.

Although most lesions are thought to have a traumatic origin, other possible causes include defect of ossification, repetitive mechanical stress, and ischemia. ${ }^{8,9}$ The main indication for allografting includes talar defects that are $10 \mathrm{~mm}$ or greater. The lesions are often missing articular cartilage, or the remaining cartilage is soft and fibrillated. In the Brendt and Harty classification, these are usually stage III or IV leisons. ${ }^{10}$ Surgery is offered when the pain is unresponsive to non-operative treatment that includes medication, cast immobilization, bracing and physiotherapy. Contraindications to allografting are few in number. The major reasons are osteoarthritis of tibiotalar joint, reflex sympathetic dystrophy and avascular necrosis of the talus. ${ }^{11}$

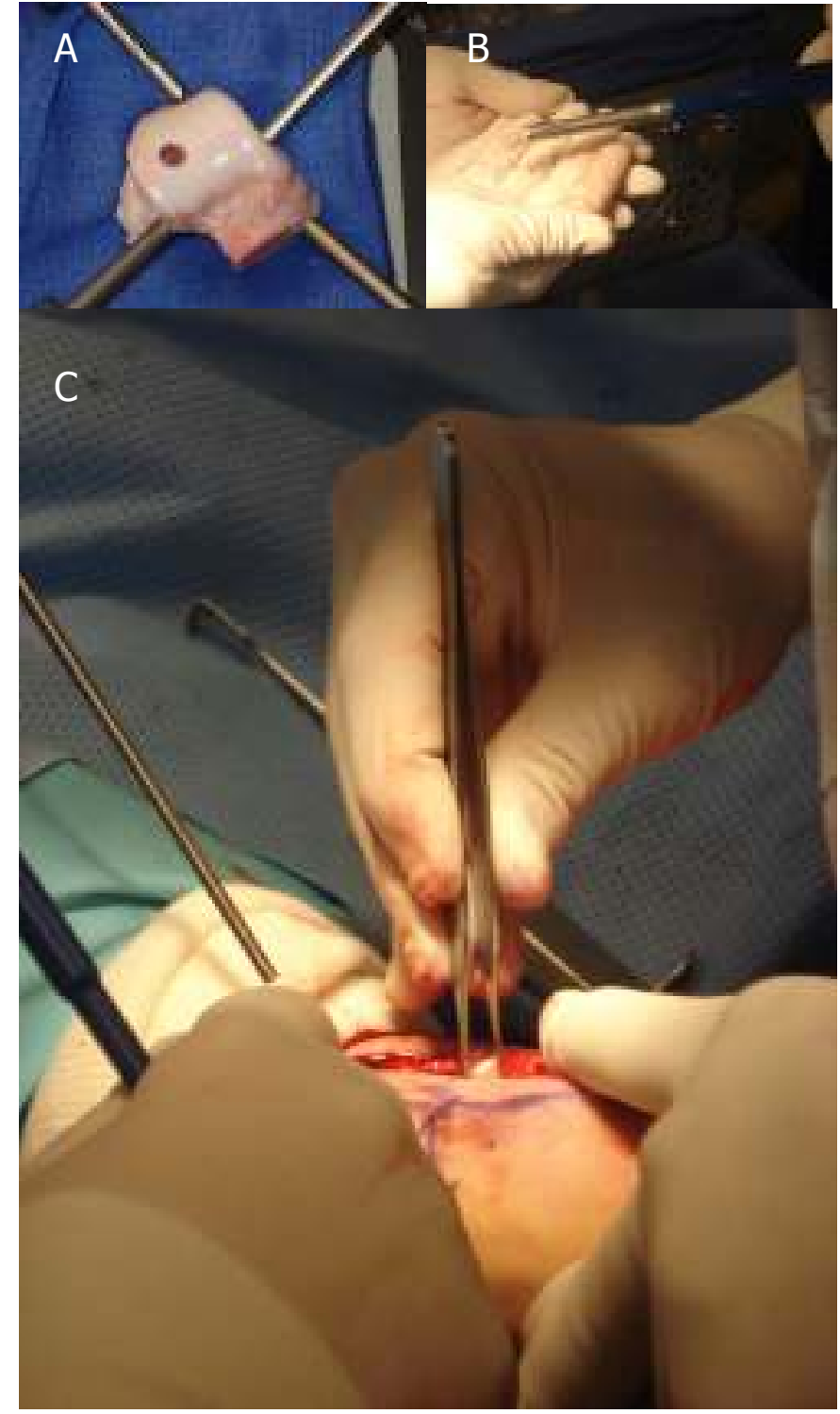

Figure 9A,B and C The $6 \mathrm{~mm}$ donor plug is harvested from the talus (A), $12 \mathrm{~mm}$ of bone plug is removed (B) and then transferred to the patient's talus. (C)

There is extensive evidence in support of autograph and allograft replacement of osteochondritis dissecans. Hangody, et al., were the first to report their early and intermediate results. They used the ipsilateral knee as a donor site and found good to excellent long term success in 34 out of 36 patients at an average of 4.2 years. ${ }^{12} \mathrm{Al}-\mathrm{Shaikh}$, et al., reports their results using the OATS procedure for treatment of the large OCD lesions of talus. Seventeen out of nineteen patients $(89 \%)$ were satisfied with their results. ${ }^{13}$ 


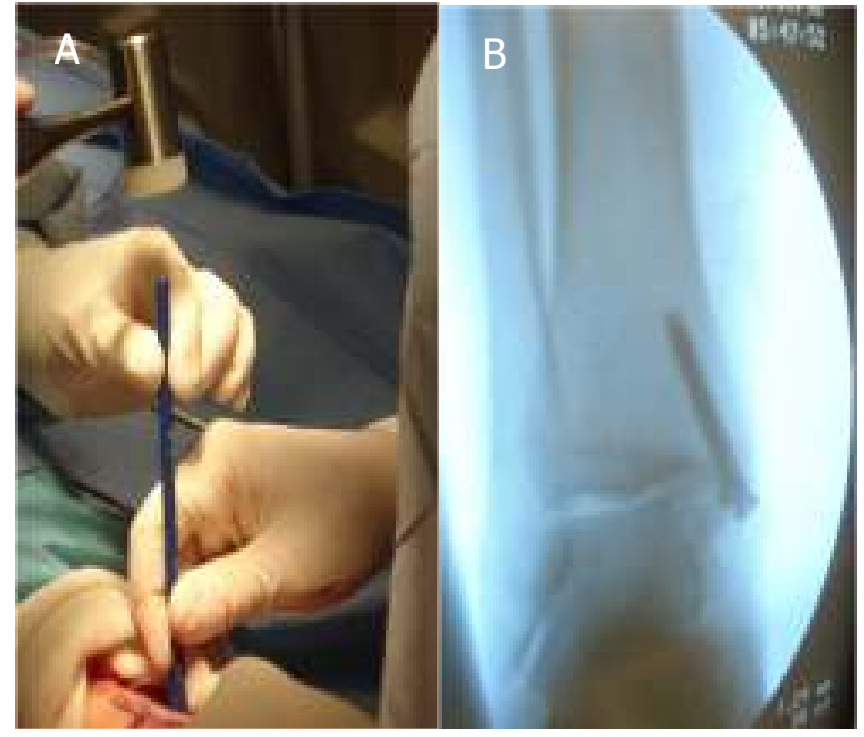

Figure 10A and B The graft is tapped into the talus. (A) Intra-operative fluoroscopic view showing the two $4.5 \mathrm{~mm}$ cannulated screw fixation of medial malleolus after graft implantation. (B)

Gross, et al., were the first to use fresh osteochondral allografts in the treatment of large OCD lesions of talus. They had 9 patients who underwent fresh osteochondral allograft transplantation from the tali of fresh human cadaver. Six grafts remain in situ with a mean survival of 11 years. ${ }^{14}$ According to Gross, et al., the most common complication of fresh osteochondral allografting is resorption and failure of the graft to incorporate, which results in subchondral collapse and fragmentation of the graft.

Post operative management includes non-weight bearing for period of 12 weeks, but range of motion exercises are started once the incision is healed. After three months, patients begin protected weight bearing in a cam boot for 1 month. Full activity is allowed by 6 months.

\section{References}

1. Munro A. Part of the cartilage of the joint separated and ossified. Medical Essays and Observations 1973 4: 19. Cited in Burns RC. Osteochondritis dissecans. CMAJ 193941 (3): 232235.

2. Garrett JC (July 1991). Osteochondritis dissecans. Clin J Sports Med 10 (3): 569-593.

3. Barrie HJ. Osteochondritis dissecans 1887-1987. A centennial look at König's memorable phrase. JBJS 1987 69B (5): 693-695.

4. Kappis M. Weitere beitrage zur traumatisch-mechanischen entstehung der "spontanen" knorpela biosungen (German). Deutsche Zeitschrift für Chirurgie 1922 171: 13-29.

5. Berndt AL, Harty M. (June 2004). Transchondral fractures (osteochondritis dissecans) of the talus. JBJS 2004 86A (6): 1336.

6. Scranton PE Jr, McDermott JE. Treatment of type V osteochondral lesions of the talus with ipsilateral knee osteochondral autograft. Foot ankle Int 2001 22: 380-384. 7. Arthrex Med. Inst. GmbH. Single use osteochondral Autograft Transfer System (OATS) and Small Joint OATS Sets, www.artherax.com (accessed 28 ${ }^{\text {th }}$ June 2010).

8. Obedian RS, Grelsamer RP. Osteochondritis dissecans of the distal femur and patella. Clin Sports Med 1997 16:1 57-174.

9. Steadman JR, Rodkey WG,Rodrigo JJ. Microfracture :surgical technique and rehabilitation to treat chondral defects. Clin Ortho Relat Res 2001 391: 362-336

10. Brendt AL, Harry M. Transchondral fractures of the talus. JBJS 1959 41A: 988-1018.

11. Meehan RE, Brage ME. Fresh osteochondral allografting for osteochondral defect of the talus. Techniques Foot Ankle Surg 2004 54: 53-61.

12. Hangody L. Kish G, Kárpáti Z, Szerb I, Eberhardt R. Treatment of osteochondritis dissecans of the talus: use of the mosaicplasty technique. Foot Ankle Int 1997 18: 628-634.

13. Al-sheikh RA, Chou LB, Mann JA, Dreeben SM, Prieskorn D. Autologous osteochondral grafting for talar cartilage defect. Foot Ankle Int 2002 23: 381-389.

14. Gross AE, Agnidis Z, Hutchinson CR. Osteochondral defect of the talus treated with fresh osteochondral allograft transplantation. Foot Ankle Int 2001 22: 385-391. 